we are brought face-to-face with the undeniable wholeness of the organism. A case has been made out for the view that the over-emphasis of any single aspect, while the whole is not kept in proper perspective, will almost certainly lead to the fabrication of unstable theoretical superstructures, destined to crumble because they have not been based on the fundamental reality of organic wholeness. This is a matter which concerns all botanists, though each, according to his capacity, must perform his detailed work in a particular field. But whatever that field may be, he will at one time or another be concerned with some aspect of the distinctive growth-pattern of the organism which he is investigating; this, it need scarcely be said, is of paramount interest to the morphologist at large. An interesting contrast that has been drawn between the 'substance-minded' and the 'relation-minded' man is relevant to the present discussion. "The substance-minded type of thinking," says A. H. Hersch, 1941, "is unquestionably the older, both in the individual and the race. It has all the tenacity of original sin. In morphology it has given us representative particles, preformation, the transmission of a cquired characters, and such morphochemical hybrids as bristle-producing, facet-forming substances, and so on. The morphologist, when substance-minded, thinks of the developmental pattern in terms of the visible structural characteristics from stage to stage. In short, he thinks in terms of a series of pictures. But when relation-minded, the morphologist recognizes that the pattern at any moment is the expression of the events which produce it, and attempts to gain a knowledge of the durations and rates, and relative durations and relative rates of the component processes in the developmental nexus. Consequently, instead of thinking in terms of a series of pictures, the relation-minded morphologist tends to think in terms of the non-picturable. If the problem of the developmental pattern is similar to the problems of the more exact sciences, then no doubt in time a system of equations will be developed to facilitate our thinking about it".

There is the modern outlook on one aspect of morphology. While it is evident that certain comparative studies and all fossil studies will continue to conform to the older pattern, the new point of view suggests great possibilities for further exploration. The feasibility of pursuing these investigations to a successful conclusion will in large measure be determined by the existence of the tools to do the job. Some of these are already at hand. Here I have in mind certain major biological works recently published or reissued, for example, D'Arcy Thompson's "Growth and Form" (2nd edn.), Needham's "Biochemistry and Morphogenesis" and Child's "Problems of Pattern and Development". Each tends to emphasize a particular aspect, but taken together they afford both the morphologist and physiologist a working knowledge of the several biochemical, physical, physiological, temporal and spatial factors which, at one or another stage of development, may be operative in moulding the distinctive form of the organism.

The publication of a major work, such as any one of those mentioned above, or of a first-class text-book, is an event of rather occasional occurrence, and depends on particular individuals twho possess the experience, capacity and urge to attempt a synthesis. Now, the point of view conveyed in Hofmeister's general morphology, with appropriate modernization and thereafter subject to progressive integrated development, would appear to represent a desirable central aim in botanical science with which few would disagree. With this as a focal point, it is cogent to inquire how we are to make the best use of the data of each of the special branches, having in mind the volume of such literature, the present tendency of individual workers towards intensive research in a restricted field, the fact that this may involve disability to broader vision, and the finite mental capacity of human beings. It is undeniable that the proper comprehension of the subject as a whole is suffering from the inevitable and progressive increase in specialization. How do we propose to deal with this situation ?

I claim no originality in raising this general question and offer no solution at this stage. It is evident that underlying the numerous symposia, conferences, joint-meetings and so on, that from time to time have been convened, the same or a not dissimilar point of view has obtained; but a more definite policy needs to be framed, continuously pursued and kept to the fore in our biological deliberations. The question of how this is to be done is for botanists collectively to decide. The time for doing so is at hand if a great opportunity is not to pass unheeded.

In conclusion, I wish to express my gratitude to colleagues for suggestions and much helpful criticism ; but for the opinions expressed responsibility lies wholly with myself.

\section{SCIENCE AND INDUSTRY*}

\section{By J. G. BENNETT}

\section{Director, British Coal Utilisation Research Association}

CURREN'T discussions as to the part which science 1 should play in industry are often vitiated by misconceptions as to what science and the scientific activity really are. Science is not the mere use of scientific apparatus to ascertain facts, nor the use of scientific jargon to describe them. Again, we should not use the term science to include the testing of materials and the control of technical processes as practised in modern industry. All this should be regarded as part of engineering and production technique, which only incidentally requires particular kinds of apparatus and men with a particular training. Science is not primarily a matter of technique but a specific activity of the human mind.

The scientiflc activity is as definite in its character as, for example, the artistic activity or the organizing activity, and in its highest form is as rare as either.

The basic scientific processes are observation, experiment and hypothesis formation. Hypothesis formation consists in applying to observations of natural phenomena an act of creative thought, which discovers in them a meaning which they previously did not possess. This new meaning then suggests new lines of thought and new lines of observation and experiment. The essential feature is that the new hypothesis is more than an orderly presentation of the data. It is a new view of the working of Nature, which is important as much because it is new as because it is valid.

The validity of a hypothesis is a purely relative conception, for we can never know the last word about Nature, and the whole progress of science con-

* Substance of an address at the inaugural session of the NorthFastern Section of the Institute of Fuel, Newcastle-upon-Tyne, delivered on October 18 . 
sists in discarding an old hypothesis in favour of a new one which is more fruitful at the particular stage which the science in question has reached. A hypothesis can be termed, 'valid' in so far as it fits satisfactorily a body of observed facts and enables new facts to be predicted which can afterwards be verified by experiment and observation. In other words, the hypothesis is the actual vehicle by which scientific thought is carried forward.

The essence of the scientific method is this combination of observation and experiment with the formation of hypothesis. Science is not the working to some predetermined plan or schedule to find an answer to a specific question. In this lies the essential distinction between science and engineering. Any industrial process or industrial development, unless it be wild speculation, must set before itself a clearly defined aim, and the industrialist must calculate in advance the material resources which he can bring to bear and the resistance which he will have to overcome. He must have an assurance of success within what is called 'a fair commercial risk'. It is upon the engineer that the industrialist relies to provide him with the technical means for carrying the project into effect. There is an element of uncertainty in every enterprise, and the task of the engineer is to reduce that element to a minimum. However bold the project may be, he must take all possible steps to ensure that the aim specified in advance is realized within a specified time, and at a specified cost.

None of these things is possible for science. Science is continually reaching out into the unknown. It cannot calculate in advance either the results which it hopes to obtain or the time which they will take to get or their cost. Any attempt to force scientific endeavour into predetermined rigid channels destroys its very essence. The result may be useful, but it is in the. highest degree improbable that it will be the creation of anything new.

The whole significance of the relations between science and industry lies in this-that it is science alone which can produce new knowledge differing not merely in precision and extent, but also in kind, in actual quality, from that which existed before. The industrial history of the past two hundred years shows. clearly where the impact of science has been truly effective. The electrical industry owes its development to the scientific work, that is the com. bination of experiment and hypothesis formation, of men like Faraday, Clerk Maxwell, Hertz and Röntgen. The fine chemical industry is founded on the experiments and hypothesis formation of men like Perkin, Kekulé, Fischer and Baeyer.

It is only in the present century that the attempt has been made to bring the scientific method, properly so-called, into industry as an effective part of its operations, although it should be noted that in the highly productive period between 1750 and 1900 , soientific men were themselves very much interested in the practical significance of their discoveries. The new idea that there are two kinds of scientific workers to be called respectively 'fundamental' and 'applied', one concerned with the advance of knowledge for its own sake and the other with the material results of scientific work, is an artificial one and is highly misleading. The collected scientific papers of men like Benjamin Franklin, Humphry Davy, Liebig, Pasteur and Kelvin make it clear that they regarded the pursuit of knowledge and the application of knowledge as an indivisible whole. There is no suggention of a conflict of motive in their scientific work. It has been a retrograde step in the present century to try to distinguish between fundamental and applied science or between 'pure' and 'commercial' men of science. There is only one kind of science, and that is the observation of natural processes, the devising and conduct of experiments and the formation of hypotheses to account for the results.

The question is sometimes asked whether there is a valid distinction between an engineer and a scientific worker. There is certainly such a distinction, for the engineer is not concerned with hypotheses, and his attitude to observation and experiment should be essentially different from that of the scientific $m-n$. The engineer's object is to make things work. He is not interested in new knowledge for its own sake. He dislikes accidents and tries to avoid being confronted with unexpected occurrences. The man of science is above all interested in the unexpected. He does not in the least mind making mistakes, providing that they teach him something. His most fertile raw material is the experiment that goes wrong, giving a result that cannot be explained in terms of existing knowledge or theories.

A survey of the elements in industrial progress would not be complete without reference to the inventor. The inventor belongs to a different category and must not be confused either with the scientific man or with the engineer, though of course it is possible to have inventors who by training are scientific men and inventors who are engineers. The true inventor is not really concerned with knowing why, like the scientific man, or knowing how, like the engineer. His urge is to create; he is interested in novelty for its own sake, and he prefers to do something in a new way even if at first sight it may not offer obvious advantages over the old ways.

It is particularly important to recognize the difference in the contributions which the man of science and the inventor have to make to the progress of industry, because, on the whole, in the future, the importance of the man of science is likely to grow and that of the inventor to diminish. This is because the inventor shows to the greatest advantage where technique is primitive, and the man of science becomes more and more effective as technique is advanced.

One other misconception that needs to be removed is that 'scientific' means 'meticulously accurate'. So far from the man of science being interested in exact measurement for its own sake, he would be the first to agree that mere measurement has little value in itself. Very often rough exploratory experiments, máde to find out whether things will happen in the accepted way or not, have led to far more important discoveries than a host of accurate measurements made with costly apparatus and no creative idea behind them.

To sum up, it may be stated that the true opposite of science is empiricism. Empiricism consists in using the results of observation and experience without attempting to understand their meaning, that is, without forming a hypothesis. A very great deal of what goes by the name of scientific research, particularly in industry, is empirical, and is therefore unlikely to lead to new knowledge and new points of view. The empirical attitude is right and indeed indispensable in the engineer, but it is wrong in the scientific worker.

With this outline of the true nature of science, attention can be turned to the question of the position of science in industry. There are essentially three 
partners in the enterprise of bringing a scientific discovery into general use. The first is the scientific worker who discovers the new piece of knowledge. The second is the engineer who combines that new knowledge with existing knowledge and experience to make something which will work on whatever scale may be required. Third, there is the industrialist whose judgment, powers of organization and management provide the engineer with the conditions required for his activity and convert the enterprise into what is known as a going concern.

These three partners do not speak the same language, and are liable to misunderstand one another in a very dangerous way in their attempts at intercourse through the medium of garbled translation. A scientific worker is apt to view with impatience the insistence of the industrialist upon the fulfilment of certain practical conditions before he is ready to bring his resources and organizing capacity to bear on a new discovery. On the other hand, the scientific man's attempt to interpret in concrete terms of commercial production what is really a new way of thinking about the world, is apt to convey either an impression of undue optimism or else of mere vagueness and muddle. Is it then the engineer who can serve as the intermediary between the man of science and the industrialist ? This would be a mistaken solution, for engineers are essentially conservative. They rightly prefer to rely on estab. lished practice or the minimum departure from it to meet the requirements of a given problem. It is the engineer's duty so far as possible to minimize risks.

The position becomes clearer when the characteristice of a successful industrialist are examined. $\mathrm{He}$ must have imagination and be receptive to new ideas. Above all, he must have a capacity for seeing the possibilities inherent in a situation earlier and more clearly than his competitors. He must have judgment to weigh successfully the favourable and the adverse factors in an enterprise. In other words, he must be able to see not only the possibilities but also the difficulties in a realistic way.

Now these are just the qualities which should be applied to a new piece of scientific knowledge if it is to be used rapidly to the greatest effect. It is by combining the outlook of the man of science with that of the industrialist that the significance of a new discovery can best be gauged. It is only rarely that a scientific man has also a natural capacity for industrial insight and judgment, and is able himself to direct his work into productive channels. The conclusion is therefore reached that the man of science and industrialist are natural allies. They have more in common than either usually can appreciate, but it is difficult for them to wdrk together not merely because they speak different languages but also because they deal with different kinds of facts. Yet any industry, where the industrialists and scientific men really come together, will make technical progress of a kind that has not been seen since the beginning of the industrial epoch. This cannot be achieved by attempts on the part of the scientific workers to popularize their ideas, or by industrialists seeking to gain a smattering of science. It can only come if scientific men take the trouble to study and understand the kinds of facts which form the subjectmatter of industrial activity, and also if the industrialists try to understand what is meant by the formulation of a new scientific hypothesis. Neither of these two things is so difficult as might be thought. The mistake that is made at present when the man of science tries to explain his work to industry, is that he tends to describe experiments and observations, to give numerical examples, or attempts to forecast some practical application. He does not try to convey the meaning of his work, the new point of view which he has reached. This is what really matters in the scientific method, for this is the true creative work which the man of science alone can do.

\section{THE ARGENTINE EARTHQUAKE}

\section{BY ERNEST TILLOTSON}

$\mathrm{O}^{\mathrm{N}}$ January 15 at about 8.51 p.m. (local time) one of the strongest earthquakes of Argentine histery occurred in the Andean Province of San Juan. The epicentre of the earthquake was near the chief town in the province, San Juan, which is situated at latitude $31^{\circ} 38^{\prime} \mathrm{S}$., longitude $68^{\circ} 38^{\prime} \mathrm{W}$., and at this place as well as in the nearby villages there was great destruction of property and loss of life. In addition to San Juan Province, the Provinces of Cordoba, Mendoza and Larioja were affected, the latter seriously. The shock was felt throughout most of the remainder of the Argentine, and also in Chile and in Uruguay. It was recorded on seismographs at many observatories throughout the world, including some in Great Britain. At La Plata it was recorded very strongly, and at Buenos Aires the recording suddenly ceased nearly as soon as it began owing to the violent, large amplitude earth waves being too great for the pendulum, which became unhinged. The recording needles of the instrument were also broken.

In San Juan, a city with a population of about eighty thousand people, about two thirds of the buildings immediately collapsed, and others were damaged in varying degrees. Among the large buildings thus affected were the cathedral, numerous churches, Government House, municipal buildings, the railway station and the post office. Fissures and fault cracks appeared in the streets. Electric cables were broken, gas.mains were shattered, water pipes were burst open, and telephone communication within the city and to the outside world ceased. Roads, especially the narrow ones, were blocked with the debris of crashed buildings, and rail traffic was stopped by fissures, fallen debris and twisted rails. In the city fires raged, having been started by the shaking of hot coals from the fireplaces, by gas escapes and by electric short circuits. Even if the fire brigades could have got to them, there would have been no water supply, and so they burned themselves out unchecked. Unfortunately, at the time many people were in cafés, cinemas and restaurants and were trapped in the buildings and narrow streets. The death roll is undoubtedly high, and three thousand bodies have so far been found and burned. More than another three thousand are injured, and when the casualties in the surrounding villages are counted the death-roll may be as high as five thousand. Fortunately rail communication with Mendoza was quickly resumed, and radio communication with the city was found possible. Drinking water was sent from Mendoza, one hundred miles away. Many of the people are now living in tents and relief work is in progress. San Juan is to be completely evacuated and cleared, and when it is rebuilt it will be spacious and the buildings will be of earthquake-proof design. The evacuation would 